\title{
RANCANG BANGUN ALAT SANDBLASTING SEBAGAI PEMBERSIH KOTORAN PADA PERMUKAAN LOGAM
}

\author{
Faisal Arif Pambudi ${ }^{1}$, Viktor Naubnome ${ }^{2}$, Najmudin Fauzi ${ }^{3}$ \\ ${ }^{1,2,3}$ Teknik Mesin, Universitas Singaperbangsa, Indonesia \\ ${ }^{1} 1610631150043 @$ student.unsika.ac.id
}

\begin{abstract}
ABSTRAK
Sandblasting adalah salah satu dari cara pembersihan permukaan terutama logam supaya kotoran seperti karat, oli, dan cat yang terdapat pada permukaan logam dapat dibersihkan. Proses sandblasting dilakukan dengan menembakan bahan abrasive dengan tekanan udara tinggi kepermukaan logam sehingga kotoran yang menempel akan terkikis dan rontok. Tujuan dari penelitian ini adalah untuk merancang dan membuat sebuah alat sandblasting dengan biaya yang terjangkau untuk industri manufaktur kecil menengah. Metode yang digunakan dalam penelitian ini dibagi berberapa tahap. Tahap pertama adalah mendesain alat dengan aplikasi gambar teknik serta menentukan alat dan bahan yang diperlukan. Tahap ini juga akan menentukan kenyamanan dan keamanan bagi operator yang mengoperasikan alat sandblasting ini. Tahap kedua adalah merakit alat yang sesuai dengan desain gambar dan alat serta bahan. Tahap terakhir adalah uji coba alat sandblasting dengan menggunakan spesimen plat baja karbon rendah SS400 yang berkarat. Semua tahapan tersebut dilakukan di Laboratorium Teknik Universitas Singaperbangsa Karawang.
\end{abstract}

Kata kunci: rancang bangun, sandblasting, permukaan logam, keamanan, kotoran

\begin{abstract}
[Design and Build a Sandblasting Tools As a Dirt Cleaner On Metal Surface]. Sandblasting is a method of cleaning surfaces, especially metal so that dirt such as rust, oil and paint on metal surfaces can be cleaned. The sandblasting process is carried out by firing an abrasive material with high air pressure onto the metal surface so that the dirt that sticks to it will be eroded and fall off. The purpose of this research is to design and manufacture an affordable sandblasting device for small and medium manufacturing industries. The method used in this research is divided into several stages. The first stage is designing tools with the application of technical drawings and determining the tools and materials needed. This stage will also determine the comfort and safety for the operator who operates this sandblasting device. The second stage is assembling the tools according to the design drawings and tools and materials. The final stage is to test the sandblasting tool using a rusted specimen of low carbon steel plate SS400. All of these stages are carried out at the Engineering Laboratory of the Singaperbangsa Karawang University.
\end{abstract}

Keywords: design and build, sandblasting, metal surface, safety, dirt

\section{PENDAHULUAN}

Hasil produksi yang maksimal adalah hal yang wajib diperhatikan pada setiap perusahaan yang bergerak di Industri manufaktur. Dalam hal ini, perusahaan membutuhkan peralatan yang mampu memenuhi kebutuhan utama yaitu proses cleaning. Peralatan cleaning yang dibutuhkan harus cepat dan efisien sehingga dapat menangani produk secara masal, berkualitas tinggi, dan harga yang terjangkau. Peralatan yang sesuai dengan kriteria perusahaan manufakturing tersebut adalah Sandblasting.

Proses Sandblasting adalah suatu cara pembersihan permukaan logam dengan cara menembakan material atau bahan abrasive seperti biji besi atau pasir kasar sehingga permukaan logam dan bahan abrasive saling bergesekan dengan tujuan menghilangkan kotoran seperti karat, oli, cat lama sehingga bahan pelapis seperti cat dapat merekat kuat. Pada proses sandblasting, material abrasive yang digunakan biasanya berbentuk butiran kecil yang ukuran acuannya adalah mesh. Jadi pengoperasian alat sandblasting yang dilakukan di 
tempat terbuka akan menimbulkan pencemaran udara oleh debu yang berbahaya jika terhirup. Secara teknis, pada proses cleaning oleh alat sandblasting dilakukan dengan cara meletakan material yang akan di semprot di lantai barulah setelah itu ditembakan. Kelemahan proses ini yaitu harus mengumpulkan pasir yang sudah ditembakan dengan sapu dan serokan yang memakan waktu yang cukup lama. Solusi dari masalah tersebut adalah dibuatnya sebuah Blasting Room yang mengatasi masalah pencemaran debu dan pengumpulan pasir. Jadi tujuan dari penelitian ini adalah sebuah alat sandblasting yang ditambahkan sebuah ruangan khusus yaitu blasting room untuk proses pengerjaan supaya operator dapat terhindar dari bahaca pencemaran debu serta mempermudah pengumpulan bahan abrasive yang sudah ditembakan.

\section{METODE}

Metode yang digunakan dalam penelitian ini dapat dilihat dari diagram alir pada gambar.

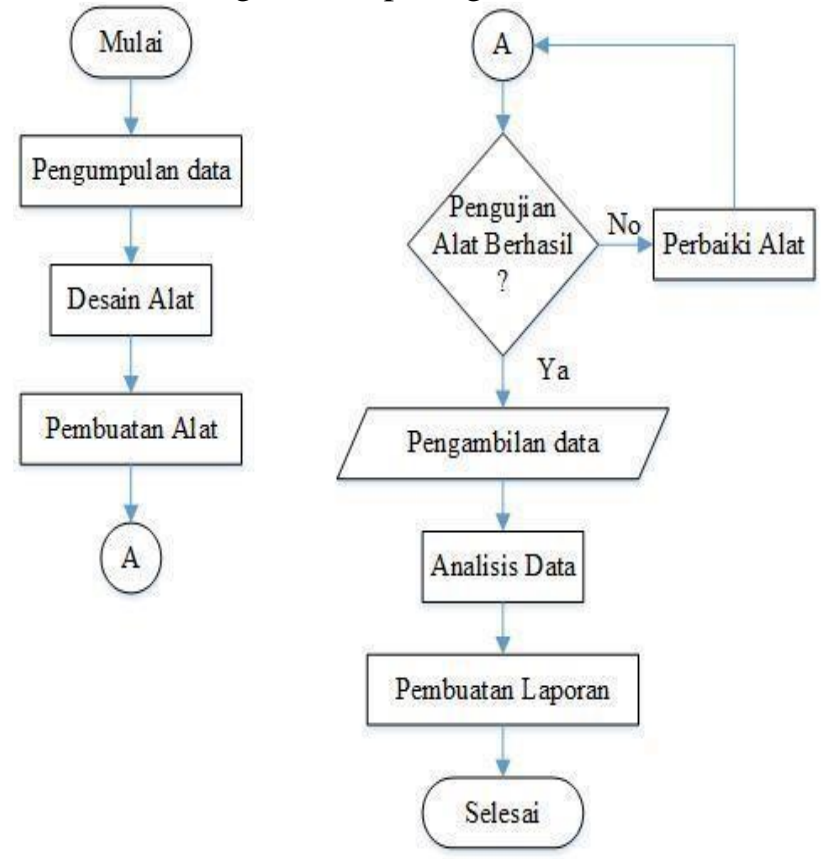

Gambar 1. Flowchart Penelitian

\section{Tahap Perencanaan}

Tahap yang pertama adalah perencanaan yang dimulai dari studi kasus lapangan maupun studi literatur. Data yang didapatkan akan digunakan untuk menghasilkan draft gambar dan daftar alat dan bahan yang diperlukan. Hasil yang didapatkan akan dituangakn didalam gambar dengan menggunakan aplikas Inventor 2014 yang dikerjakan di Laboratorium Teknik Mesin Universitas Singaperbangsa.

Ada berberapa komponen penting dari alat sandblasting dari penelitian ini seperti kompresor, sandpot, dan blasting room.
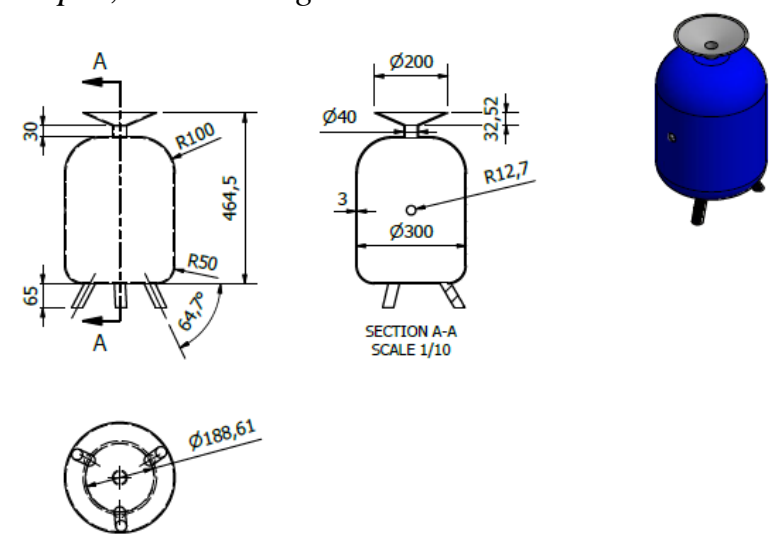

\section{Gambar 2. Desain Sandpot}

Sandpot ini berfungsi sebagai tempat penampung bahan abrasive seperti pasir yang nantinya akan ditembakan dengan udara bertekanan dari kompresor. Bahan yang diperlukan untuk membuat sandpot ini bisa dari tabung gas atau tabung freon yang tahan terhadap tekanan lebih dari 8 bar.
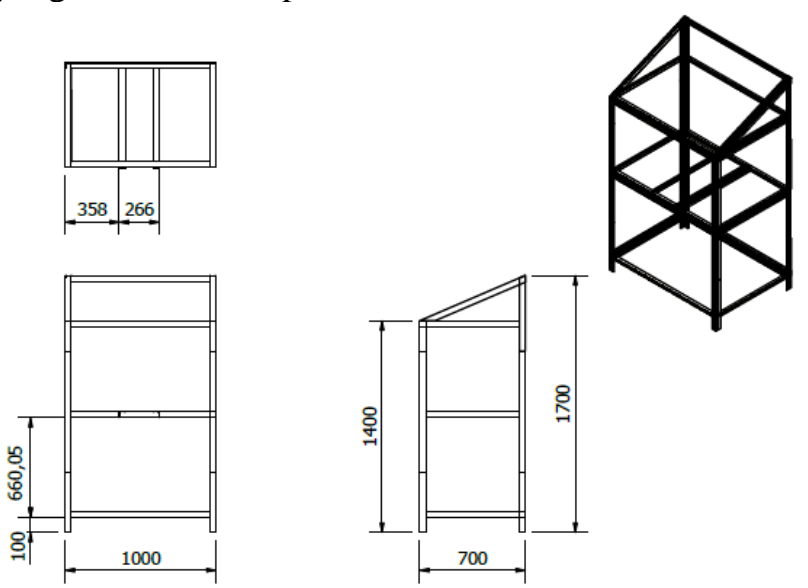

Gambar 3. Desain Rangka Blasting Room

Desain rangka blasting room nantinya akan digunakan sebagai tempat khusus proses sandblasting. Fungsi blasting room ini untuk melindungi operator dari pencemaran debu serta memudahkan pengumpulan kembali bahan abrasive yang telah ditembakan. 

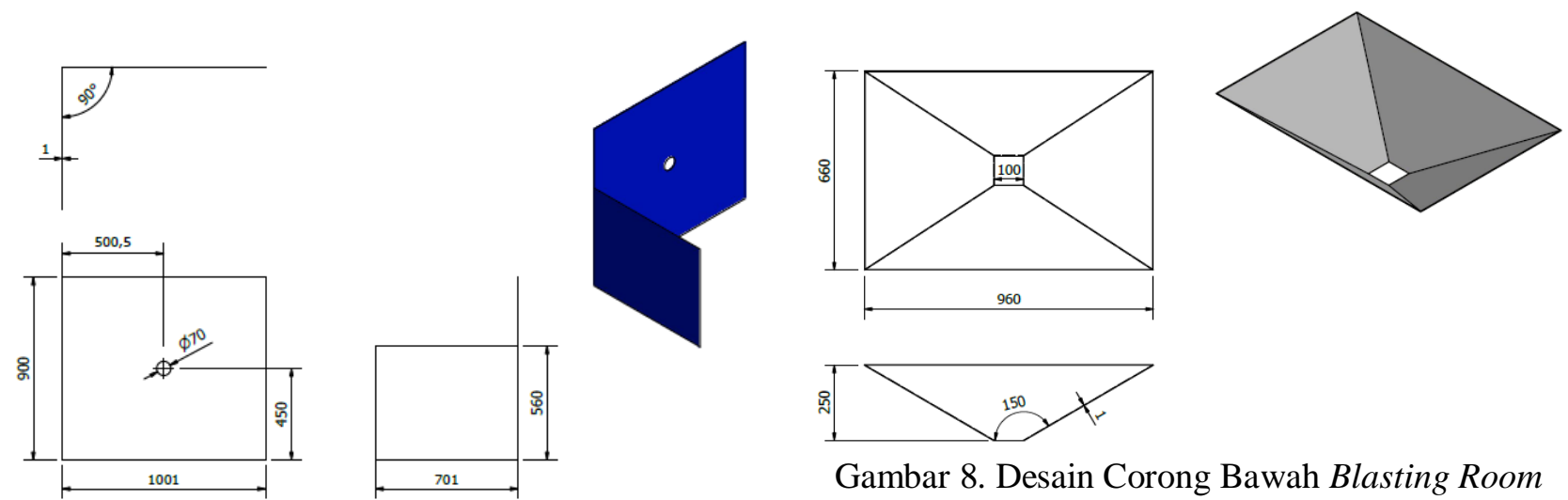

Gambar 8. Desain Corong Bawah Blasting Room

Gambar 4. Desain Cover Samping Blasting Room
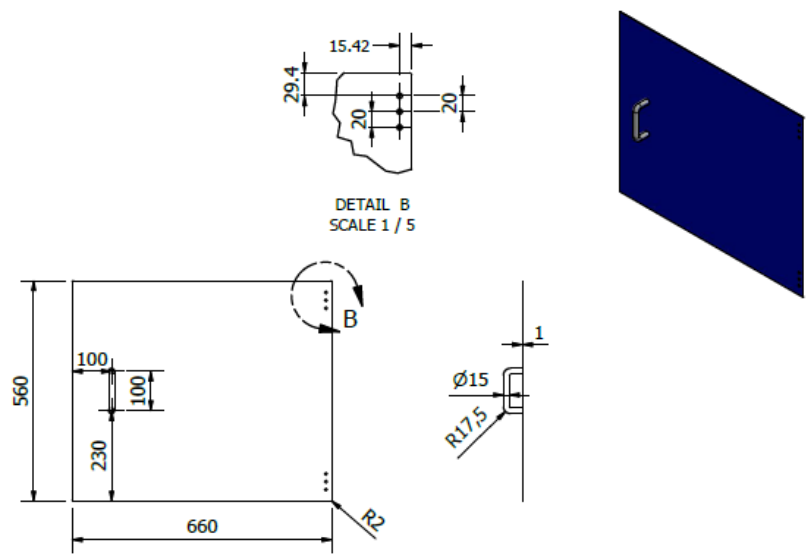

Gambar 5. Desain Pintu Blasting Room

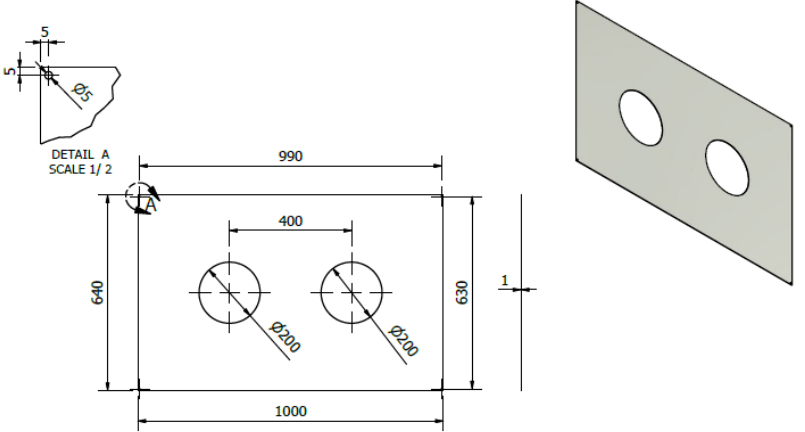

Gambar 6. Desain Cover Depan Blasting Room
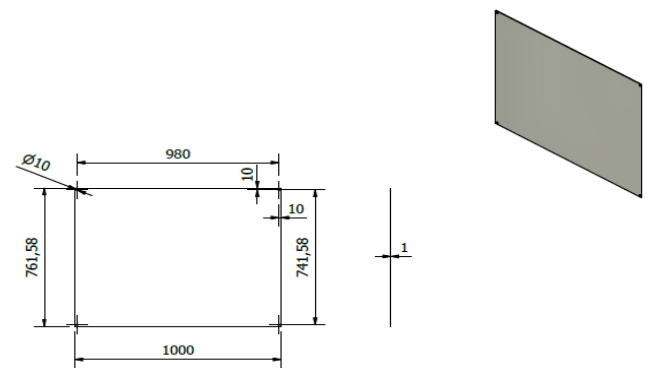

Gambar 7. Desain Cover Atas Blasting Room
Bahan-bahan yang diperlukan untuk membuat blasting room ini yaitu kayu meranti $3 \times 3 \mathrm{~cm}$ sebagai rangka, Melamin sebagai cover samping, depan, atas, dan pintu, kaca akrilik, serta terpal atau kain sebagai corong bawah yang berfungsi mengumpulkan bahan abrasive yang telah ditembakan disatu titik. Selang yang digunakan untuk mengalirkan udara serta bahan abrasive yaitu selang udara TEKIRO berdiameter $1 / 2$ inch yang mampu menahan tekanan hingga $300 \mathrm{kgf} / \mathrm{cm}^{2}$ dan nozzle angin berdiameter $0,5 \mathrm{~mm}$ berbahan keramik.

Alat yang paling penting dari alat ini adalah kopresor. Kompresor berfungsi untuk membawa bahan abrasive dengan tekanan udara tinggi yang nantinya akan ditembakan ke benda kerja. Spesifikasi kompresor yang digunakan yaitu:

Tabel 1. Spesifikasi Kompresor

\begin{tabular}{|l|l|}
\hline \multicolumn{2}{|c|}{ Spesifikasi Kompresor Izumi SILENT OL 07 24 } \\
\hline Kapasitas Tanki & $24 \mathrm{Liter}$ \\
\hline Power & $550 \mathrm{~W}$ \\
\hline Voltage & $220 \mathrm{~V} / 50 \mathrm{~Hz}$ \\
\hline Speed & $1450 \mathrm{Rpm}$ \\
\hline Insulation Class & $\mathrm{B}$ \\
\hline Air Output & $112 \mathrm{~L} / \mathrm{Min}$ \\
\hline Working Preassure & $8 \mathrm{Bar}$ \\
\hline Diameter Silinder & $64 \mathrm{~mm}$ \\
\hline Berat Bersih & $18.5 \mathrm{Kg}$ \\
\hline Kapasitor & $25 \mathrm{uF}$ \\
\hline Load Current & $3.7 \mathrm{~A}$ \\
\hline
\end{tabular}

\section{Tahap Perakitan}

Setelah perencanaan selesai membahan desain serta bahan yang akan digunakan, selanjutnya adalah tahap perakitan alat. Perakitan ini memerlukan alat seperti gergaji kayu, bor listrik, mur dan baut, cutter, palu besi, paku, serta sealent seagai penutup selasela sambungan supaya debu tidak ada yang keluar. 


\section{Tahap Pengujian}

Setalah alat seleasi dirakit, selanjutnya dilakukan pengujian untuk melihat apakah alat berfungsi dengan baik atau tidak. Spesimen dari pengujian ini adalah tipe Mild Steel yaitu SS400 yang berarti baja struktural bukan stainlees steel dari standar JIS. Baja SS400 ini digunakan untuk kontrsuksi jembatan, pelat kapal laut, oil tank, dan lain-lain. Cara pengujian ini yaitu baja SS400 dalam keadaan berakarat akan ditembakan dengan bahan abrasive bertekanan tinggi untuk menghilangkan karat pada permukaan baja. Proses akan dilakukan didalam blasting room yang akan dilihat apakah debu basil proses keluar atau tidak serta melihat bahan abrasive yang telah ditembakan akan dikumpulkan disatu titik melewati corong bawah.

Tabel 2. Spesifikasi Baja SS400

\begin{tabular}{|llllllll|}
\hline Chemical elements & $C \leq 16 \mathrm{~mm}$ & $\mathrm{C}>16 \mathrm{~mm}$ & Si & Mn & $p$ & $S$ \\
& $\max$ & $\max$ & $\max$ & $\max$ & $\max$. & $\max$. \\
\hline$\%$, by mass & 0.17 & 0.20 & - & 1.40 & 0.045 & 0.045 \\
\hline
\end{tabular}
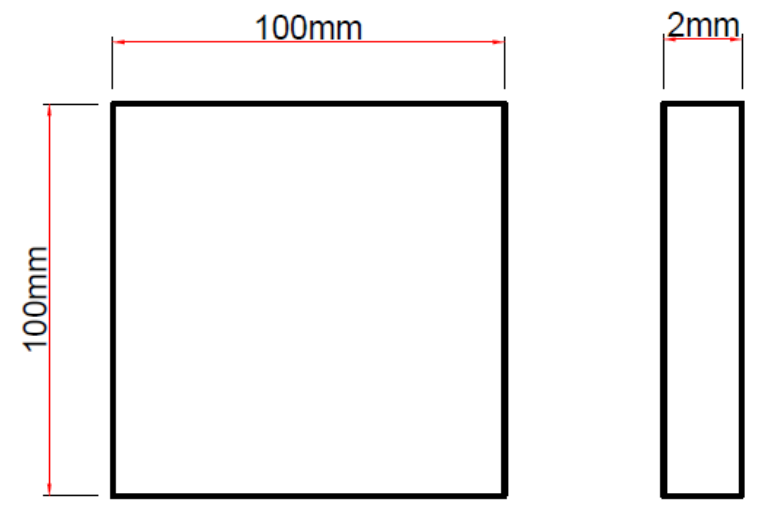

Gambar 9. Spesimen Uji Coba

\section{HASIL DAN PEMBAHASAN}

Hasil dari penelitian ini adalah dibuatnya alat sandblasting sesuai dengan desain yang sudah direncanakan di tahap pertama. Pada gambar 9 ditunjukan bagian utama dari alat sandblasting yang meliputi kompresor (1), selang angin dan pasir (2), sandpot (6), nozzle (7), dan blasting room $(3,5,8,10,12,13)$. Alat ini juga bisa ditambahkan sebuah penyedot debu seperti vacum cleaner atau exhaust fan (9) yang digunakan untuk membersihkan debu yang beterbangan didalam blasting room.

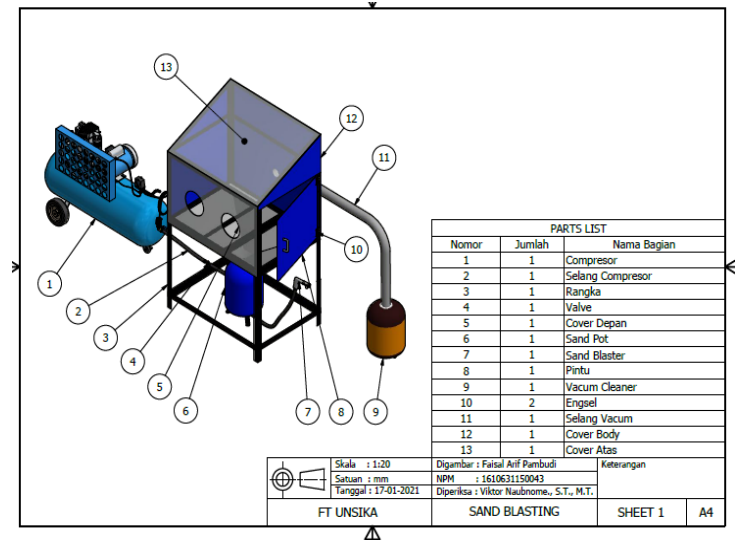

Gambar 9. Desain Akhir Alat Sandblasting

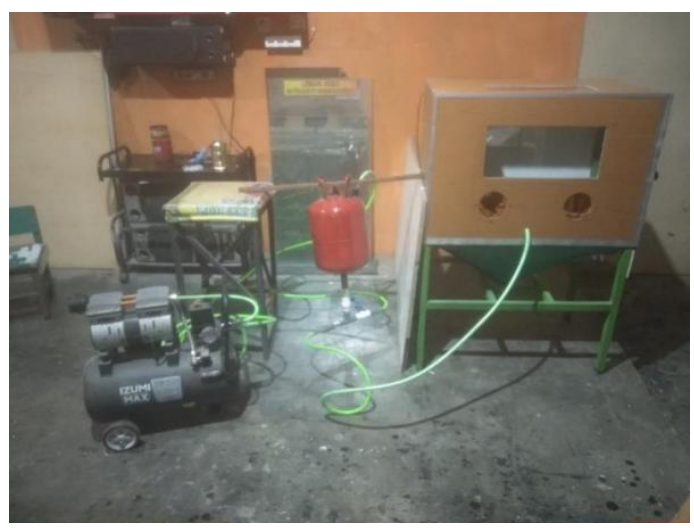

Gambar 10. Alat Sandblasting

\section{Hasil Pengujian}

Pengujian dilakukan di Laboratorium Teknik Mesin Universitas Singaperbangsa. Spesimen uji coba adalah plat mild steel SS400 yang permukaannya sudah berkarat.

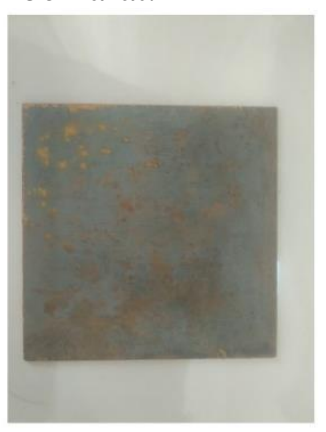

Sebelum

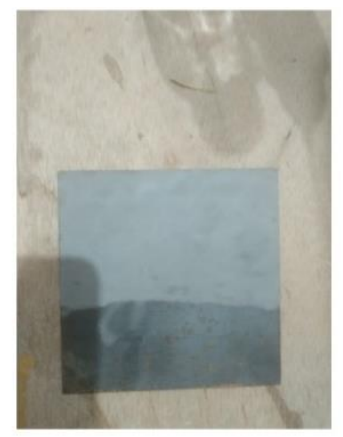

\section{Sesudah}

Gambar 11. Hasil Pengujian

Pada gambar 11 bisa dilihat plat SS400 yang permukaannya berkarat dan setelah dilakukan proses sandblasting permukaan plat SS400 menjadi putih bersih yang menandakan karat telah rontok. Tekanan yang dipakai adalah 8 bar yang dapat dilihat pada preassure gauge di kompresor dan bahan abrasive yang digunakan adalah pasir silika mesh 40. Proses 
yang dilakukan didalam blasting room terbukti tidak ada debu yang keluar karena tertutup rapat dan karena ada corong bawah maka pasir yang telah ditembakan dapat dikumpulkan di satu titik.

\section{Biaya Produksi}

Biaya untuk memproduksi alat sandblasting ini akan dipaparkan hanya biaya bahan baku saja. Biaya proses tenaga kerja dan alat diabaikan.

Tabel 3. Rincian Biaya

\begin{tabular}{|c|c|c|}
\hline Nama Barang & Jumlah & Harga (Rp) \\
\hline Kompresor $2 \mathrm{HP}$ & 1 Unit & Rp.6.500.000. \\
\hline Sandpot & 1 Unit & Rp. 80.000 \\
\hline Selang Angin $1 / 2$ Inch & 4 Meter & Rp.50.000. \\
\hline Nozzle Keramik & 1 Unit & Rp. 250.000 . \\
\hline Kayu Batang Meranti & 5 Unit & Rp. 100.000 . \\
\hline Melamin $5 \mathrm{~mm}$ & 1 Unit & Rp. 115.000. \\
\hline Valve Kuningan $1 / 2$ Inch & 2 Unit & Rp. 50.000. \\
\hline Pasir Silika & 1 Karung & Rp. 100.000 . \\
\hline \multicolumn{2}{|l|}{ TOTAL } & Rp.7.245.000. \\
\hline
\end{tabular}

\section{KESIMPULAN}

Alat sandblasting ini didesain dan dibuat untuk menghilangkan kotoran pada permukaan logam. Selain itu bisa juga untuk membersihkan keraj oli pada sela sela blok mesin motor, hasil las di tempat sempit, menghilangkan cat lama pada pagar sebelum dicat kembali, dan masih banyak lagi. Untuk segi biaya produksi harga Rp.7.245.000. masih cukup terjangkau untuk usaha Industri Manufaktur menegah dibandingkan dengan alat serupa. Kemanan operator juga dapat terjamin karena proses dilakuka didalam blasting room sehingga tidak ada pencemaran debu.

\section{DAFTAR PUSTAKA}

[1] Alwafi Ridho Subarkah. (2018). Rancang Bangun Kabinet Soda Blasting, 6(02).

[2] Aziz, L. A., \& Prassetyo, H. (2016). Usulan Rancangan Mesin Sandblasting Untuk Produk Pipa Bushing Arm Honda Crv, 4(01), 299-310.
[3] Pamungkas, S. A., \& Suwasono, B. (2018). Perancangan Ulang Alat Bantu Pengisian Pasir Abrasive Steel Grit Guna Meminimalkan Waktu Pengisian (Studi Kasus PT. Safinah Blasting). Prosiding Seminar Nasional Sains ..., 453-458.

[4] Putri, F., \& Riawan, D. (2018). Analisa Pengaruh Sudut dan Waktu Penyemprotan Terhadap Uji Kekasaran Permukaan Material Baja ST 50 Pada Proses Sandblasting. Jurnal Austenit, 10(2), 51-55 